\title{
Dramatisation As A Teaching Method In University Programs For Tour Guides And Interpreters
}

Lola Teruel, Universitat Politècnica de València Spain Maryland Morant, Universitat Politècnica de València, Spain María José Viñals, Universitat Politècnica de València, Spain

\begin{abstract}
Tour guides and heritage interpreters are central to the development of experiential tourism. This form of tourism aims at delivering memorable and personalised visitor experiences by developing activities that induce physical, emotional, spiritual and intellectual connections with a specific destination, its resources and its population. In this sense, thematic approaches to heritage interpretation allow heritage resource managers to clearly convey messages by promoting awareness and respect for heritage resources. Dimensions of competency related to heritage interpretation are explored in both formal and informal Spanish education systems. Significant learning methods are designed to achieve these dimensions of competency by allowing the student tour guide to serve the subject of an activity by dramatising interpretive content.

This paper describes the experience of the degree programme in Tourism Management at the Polytechnic University of Valencia (Universitat Politècnica de Valencia), which applies curricula that involve designing, producing and implementing dramatised tours. A critical assessment of this program is carried out to evaluate the experiences and academic progress of students and other individuals involved in the program's development.
\end{abstract}

Keywords: Experiential Tourism; Heritage Interpretation; Drama-Based Training; Tour Guides; Learning Method

\section{INTRODUCTION}

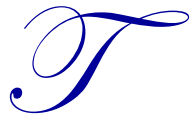

he new European Higher Education Area (EHEA) arose from a need to conduct an in-depth curricular reform of higher education programs with the ultimate aim of making European universities globally competitive through the delivery of degrees that meet the new demands of society. The authors are currently witnessing a form of educational innovation that is based on greater flexibility, transversality and interdisciplinarity. These societal shifts necessitate the development of new teaching and learning methodologies.

The field of higher education has entered a new phase in which particular attention must be paid to the use of teaching methodologies that improve teacher-student interactions, that reinforce the acquisition of practical skills among students, and that stress the use of more effective assessment tools. The aim is to move away from a focus on traditional teaching methods to an approach through which students are equipped with technical tools for acquiring skills needed in the labour force. The ultimate objective of this reform movement is to encourage students to develop stronger capacities of judgment and reflection (Ministry of Education, Culture and Sport, 2012).

For these reasons, European convergence initiatives have involved the review and adaptation of curricula used in universities, both in Spain and in other countries where graduate studies in Tourism are offered. The White Paper on Tourism (2004) categorises the various tourism sub-disciplines. A section is devoted to the development of tourism products and activities, among which the generic competencies of a tour guide are defined, differentiating guides (referring to escort guides) from guide interpreters and specialised guides (employed by cruise ships or museums, nature tours, etc.) within the profession. Intermediaries within the tourism industry, including a broad 
range of professionals associated with travel agencies and sectors involved in the development of tourism products involving receptive tour operators and tourism companies, have been demanding these professional profiles for years.

Education and labour administrations have made considerable efforts in this regard. Thus, all training levels in the field of tourism are offered through formal and informal courses that include basic, vocational, professional, and continuing training courses as well as undergraduate and master's degrees in tourism. However, within Tourism program curricula used in Spanish public and private universities, no modules teach guide-interpreters how to ascribe meaning to the tourist experience.

This paper reports the results of an innovative educational project undertaken from 2012 to 2014 (two academic years) on Year 4 of the Undergraduate Degree program in Tourism Management at the Polytechnic University of Valencia. The project trained guide-interpreters in the delivery of interpretive/educational activities. In response to current visitor demands for recreational activities, students designed and implemented drama-based tours based on practices of experiential tourism and heritage interpretation.

The syllabus was designed so that by the end of the course, students would have acquired the cognitive skills needed to guide qualitative experiences. Regarding cognitive objectives, students were taught to stay abreast of new tourism trends and to recognise the importance of promoting natural and cultural heritage through interpretation programs. Regarding objectives related to the design of qualitative experiences, special emphasis was placed on structuring themes or messages to convey to visitors and on the importance of combining messages on heritage with emotions. These objectives were met through the use of dramatised tours.

In turn, generic competencies ascribed to the degree in Tourism were developed, including tourism project design, teamwork, effective communication, and time management and planning, among others. In addition, a number of specific skills related to heritage interpretation were acquired, such as the ability to generate messages based on a central idea or theme, knowing one's audience and transmitting knowledge that can evoke emotions in visitors.

\section{New Tourism Trends: Experiential Tourism}

Experiential tourism applies themes used in active tourism, nature tourism, and entertainment activities. What differentiates this typology from other forms of tourism is its focus on generating unique, personalised, heavily emotional experiences which, evoked through activities, create personal connections with a specific place, its resources and its inhabitants.

This form of tourism appeared with the emergence of new market trends of the $21^{\text {st }}$ century. Within a relatively short period of time, there was a shift in focus from 'selling products' to 'selling experiences'. However, these concepts had already been discussed in the 1990s by authors such as Bernd Schmitt who is considered the father of experiential marketing. In 1999, Schmitt noted, "customers choose products based on the consumption experiences that they offer".

Utilising experiences and emotions involves developing an understanding of how encounters with a particular destination affect tourists and/or visitors and how a connection between the tourist and destination is created.

In turn, several studies focusing on determining consumer emotional profiles arose when several authors highlighted the importance of analysing emotional and social indicators that affect consumer decision-making (Goleman, 1996; Binkhorst, 2006; Sánchez, 2009). Other authors have referred to the commercialisation of human feelings where the primary purpose of a product is to satisfy emotional needs while generating new experiences (Jensen, 1999; Pine, 1999; Vera, 2008).

For several decades, various sectors have utilised experiences to connect with the final consumer. The most prominent efforts have been carried out in the automotive and beverage industries. Through the marketing of various 
products, promotional campaigns focused on engaging end-consumers. In 1970, The Coca-Cola Company had already launched its "The spark of life" slogan, which suggests that consuming the product is associated with moments filled with emotion and feelings of happiness. Similarly, the energy drink brand Red Bull GmbH has been identified for more than 10 years with the slogan 'Red Bull gives you wings' and, with this, the capacity to engage in high-risk activities. Other campaigns have directly engaged drivers' emotions while behind the wheel of a car, as in the case of a slogan used by carmaker BMW, 'You love driving'.

In the audio-visual fields, several studies have found close ties between viewers and fictional series, during which viewer interest shifts from the series to the tourist destination where it was filmed (Araujo, 2011). Significant examples include World Heritage Site Petra in Jordan, the shooting location of the film "Indiana Jones and The Last Crusade", where a so-called "treasure" appears in one of the most significant stone-cared monuments. Similarly, "The Lord of the Rings", shot in New Zealand, displays the country's rich natural landscape heritage.

It is evident that society demands experiences from all industries. Hence, it appears that rather than being a passing fad, experiential tourism will remain an enduring trend into the future. Consequently, both public and private sector tourist destinations must prioritise "experiential quality" by reforming the tourism sector to deliver efficiency, innovation and sustainability, as suggested in a number of Tourism Plans, such as the "Tourism Plan Horizon, 2020, Spain" (State Secretariat for Tourism, 2007). To achieve this goal, both citizens and the professional sector (guides, accommodation, restaurants, brokers, etc.) must be involved in this process. Service providers spearhead these changes through their attitudes, knowledge and interactions with visitors by way of the various services they offer.

Until recently, most interpretive programs and the majority of information provided to visitors has remained within the realm of cognitive knowledge. Consequently, professionals, and tour guides in particular, are not prepared to offer new experiences. It is evident that in most destinations, greater importance is placed on conveying knowledge and information than on delivering satisfactory experiences; this is especially apparent if one reviews the syllabi used in Spanish tour guide certification programs. While each autonomous region follows its own regulations, all regions must apply Law 17/2009 of November 23 on Free Access to Service Activities. This transposition of Directive 2006/123/EC of December 12, 2006 is referred to as the Services Directive. According to this directive, each autonomous region determines which activities may be undertaken. It appears that to perform activities of experiential tourism (although it is not explicitly mentioned), theoretical tests on geographical aspects of the Autonomous Region in question, general knowledge, historical knowledge and knowledge of at least two languages must be passed, with little emphasis placed on the tour guide's ability to design and implement tourism itineraries and even less on the guide's interpretation of heritage. Once again, this demonstrates that tour guides are not trained to address current demands to meet emotional needs. This lack of training prevents tourism destinations from enjoying competitive positioning as destinations of "experiential quality".

This lack of training highlights the need to equip specialised professionals in this field with the knowledge and skills required to meet visitor expectations while stimulating the local economy and promoting the sustainable use of natural and cultural resources.

Tour guides can no longer serve as mere informers. Rather, they must facilitate the development of emotional bonds between visitors and destinations. While experiences offered may vary, this paper focuses on the delivery of interpretive/educational experiences as one less-explored subject of experiential tourism concerns heritage interpretation.

Heritage interpretation combines elements of resource conservation with resource use and enjoyment to promote quality experiences and thus visitor satisfaction. The main interpretive approach to resource management involves the development of a Thematic Interpretation Program.

\section{Tour Guide Competencies: Thematic Interpretation}

Because thematic interpretation may be used to meet experiential tourism objectives, this section reflects on its competency standards and its definition and considers its inclusion in the curricula of Spanish universities and formal institutions. 
Thematic interpretation is defined as a strategic communication process that applies techniques that are appropriate to the target audience (visitors) and heritage resource involved (Ham, 2011). Heritage interpretation is a fairly recent discipline that has initially been linked to the field of natural heritage, and most literature in this area comes from the Anglo-Saxon world (Tilden, 1977; Ham, 1992, Beck, 1998, National Park Service, 2007). Other studies have focused on demands for heritage sites and associated consumer motivations (Lewis, 1981) and cognitive factors (Ham, 2008) and on the micro-segmentation of this demand (Christensen, 2005).

Competency standards for thematic interpretation were presented in a work by (Mendoza-Ontiveros, 2011) based on proposals that emerged from the Permanent Seminar on Heritage Interpretation by the National Park Service (Bacher, 2007). These documents present a series of highly specific competencies for heritage guideinterpreters, including the following:

1. an understanding that they are mediators in the process of forging connections between meanings inherent to a resource and audience interests.

2. a dedication to understanding, acknowledging and creating opportunities for audiences to forge their own intellectual and emotional connections based on meanings inherent to the resource

3. an understanding of their role in the generation of knowledge on resources, audiences and interpretive techniques

4. an ability to apply theoretical fundamentals of interpretation that are pleasant, organised, relevant and thematic (Ham, 1992)

5. an ability to convey a message through interpretive activities

6. an awareness of the need to reflect on principles of interpretation and on improvements in their practices

7. a dedication to developing and implementing techniques to assess the effectiveness of their products and interpretive activities and optimise them

Heritage interpretation thus emphasises the importance of guide-interpreters as key conservationists of protected areas (Morales, 2000). Heritage interpretation thus involves the acquisition of knowledge in a friendly and voluntary manner that, through guide-interpreters, is illustrated by fusing intellectual and emotional knowledge. In this sense, during processes of thematic interpretation, guide-interpreters face the challenge of adapting messages conveyed to achieve the objectives of other traditional, off-line interpretive media. According to Ham (1992) and Morales (2000), guide-interpreters connect visitors with sensory, emotional and intellectual experiences.

In line with these competency standards for thematic interpretation and taking into account that tourism graduates may have later become guide-interpreters, an attempt has been made to examine university curricula offered in Spain on this subject. Thus, while competencies of the guide-interpreter are defined in undergraduate programs in Tourism based on the White Paper on Tourism by Spanish universities, these are merely generic competencies that do not meet the criteria listed above regarding heritage interpretation. Emphasis is placed on certain competencies, such as an awareness of initiatives that promote cultural heritage; an understanding of how destinations, tourist facilities and business sectors function at the global level; and interest in identifying technical planning, tourism infrastructure and facility requirements.

Regarding the curricula of Spanish university degrees in Tourism and endeavours to include subjects related to heritage interpretation, it is worth noting that competency standards allow for student training services that enhance tourism projects related to natural and cultural heritage, strategic planning, heritage conservation, visitor management, information and communication techniques, etc. However, courses focusing on these competencies are not widespread. A review of 54 Spanish universities offering undergraduate degrees in Tourism showed that cultural heritage curricula largely focused on descriptive knowledge on historical periods. Few curricula reference natural heritage from the perspective of resource enhancement and conservation. Among these were courses entitled "Historical and Artistic Heritage" and "Cultural Heritage and Territorial Tourism Resources". Courses that required tour guides to combine resource interpretation skills with guiding tasks were minimal ${ }^{1}$. Among these courses, only

\footnotetext{
${ }^{1}$ The identified curricula come from the University of Barcelona, Charles III University of Madrid, the Complutense University of Madrid, the University of A Coruña, the University of Girona, the University of Málaga, the Polytechnic University of Valencia, and the University of Salamanca
} 
eight Spanish universities offered highly specialised courses in historic heritage interpretation and management and/or group guiding. Despite the importance of such competencies to tour guiding, few elective courses that focus on these skills are available to students.

It must be stressed that Spanish vocational training in the hotel and catering industries is offered through university degrees in Tourist and Visitor Guiding. These degree programs offer courses related to group guiding for natural and cultural heritage interpretation. Among other competencies, the authors have identified those related to i) group leader training, ii) tour package creation, iii) itinerary creation and design and, occasionally, iv) heritage interpretation for tourist satisfaction.

In other European countries and on other continents, heritage interpretation is included in university curricula through courses and diplomas, though they are not always offered through tourism programs, but rather through architecture, archaeology or history programs. Among other examples, Thompson River University's (Kamloops, Canada) Adventure Guide diploma is notable in that its specialises in specific recreational activities and geographic areas. The University of Westminster (London) also offers a Diploma of Special Study in Tour Guiding that is exclusively designed for the City of Westminster. This program trains students in the design and delivery of tours in London through a combination of historical knowledge techniques and interpretation skill sets needed for effective tour guiding.

Ton Duc Thang University (Vietnam) offers tour guide training through its Faculty of Social Sciences and Humanities that equips its students with thorough knowledge of Vietnamese culture and history. Finally, Charles Darwin University in Australia offers an online tour guide accreditation course that is required to work as a guide in Uluru-Kata Tjuta National Park. This comprehensive training program was designed by professional guides and tour operators to expand the scope of tour guide training and to ensure that the program is tailored to the operational needs of the tourism industry.

It is interesting to note that heritage interpretation forms part of the training curricula of cultural and tourism management studies, both for university and non-university students. Several national agencies also offer illustrated handbooks for tour guides in escort guiding, guide interpreting and tour guiding (the exact terms used). Among other tour guide training manuals that have been developed, notable mentions include the "Handbook of Good Practices for Tour Guides" created by the Ministry of Peru (2007) and the "Introduction to Tour Guide Service" developed by the Ministry of Tourism of Chile. In other countries, even highly specialised manuals on active tourism have been published, such as the "Training Manual for Tour Guiding in Kayaking and Snorkelling", published in 2005 under the project on coastal resources in Belize.

This review shows that tourism graduates and professionals must use heritage interpretation as a tool for achieving positive outcomes and for conveying messages that support the sustainable development of tourism destinations. The "Academy" thus is currently faced with the challenge of training versatile professionals who appreciate heritage and who make heritage accessible to visitors by offering knowledge and forging emotional ties.

\section{Dramatisation As A Tool For Thematic Interpretation}

A major benefit of thematic interpretation tools is that they allow consumers to acquire knowledge in a fun and novel manner.

The use of dramatic play for educational purposes is common in many education areas, especially in the first years of course work. Dramatic play is used as an experiential learning tool that is based on a socio-emotional educational approach that favours individual development. Using this method, the learning experience is internalised from the moment that the student is directly involved, allowing the student to act as a protagonist during the learning process. Because this process engages feelings, emotions and the mind, individuals retain information learned for longer periods. This method thus delivers the necessary socio-emotional competencies that guide-interpreters need. Hence, dramatisation is considered as an artistic form of storytelling that explores meanings (Pascoe, 1998) while adding another dimension to the interpretive experience (Bicknell, 1994). In addition to Ham (1992), several authors, such as Bicknell (1994), Powell (1995), Shively (1995), Smith (1998), Broughton (2002), Gaskell (2002) 
and Nwadigwe (2007), view dramatisation as a powerful tool for interpretation in formal and informal education settings.

Among skills that are developed through engagement in dramatisation, attention has been placed on the development of role-playing skills. Role-playing is a technique of participatory and experiential learning that emphasises the principle of 'learning by doing' (Armstrong, 2003). Emphasis must also be placed on its abovementioned benefits in the context of university education, which rarely affords students opportunities to express attitudes and feelings or to implement theoretical knowledge and skills (Errington, 1997).

Dramatised tours have been offered in the tourism industry for over a decade and are mainly available in urban and cultural environments. The technique tends to be underutilised relative to other interpretive techniques, though it has been highly successful in countries such as Australia. However, few studies have scientifically analysed the outcomes of these techniques.

The application of dramatisation techniques in delivering memorable visitor experiences necessitates the inclusion of heritage interpretation courses in university programs, and particularly those focusing specifically on tour guiding. This subject stresses the importance of heritage interpretation and its applications in experiential tourism. It complements tour-guiding techniques that are fundamental to the success of destination tours. However, as has been shown above, several more options are available.

The authors' research on teaching methods examined drama-based training programs for tour guides (Degree in Tourism Management at the Polytechnic University of Valencia). The project was divided into several parts among which a key element was included - the development of a dramatised tour as part of the Exhibition of the Network of Valencian Universities for the promotion of Research, Development and Innovation (RUVID, in Spanish) entitled "Científicas Invisibles" [Invisible Women Scientists]. The "Invisible Women Scientists" project includes various activities that are aimed at recovering and acknowledging work performed by numerous female scientists throughout history and at present. Materials placed on display are interesting but do not cater to young audiences who are accustomed to audio-visual technologies and who are difficult to impress. Given this limitation, the authors applied other techniques that more readily facilitated intellectual connection and conveyed interpretive messages while students fostered other dimensions of competency through engagement in meaningful and interactive learning processes.

The teaching project involved designing, producing and implementing three dramatised tours associated with the exhibition. Project target audiences varied from high school students to more specialised and diverse public sectors (teachers, researchers and professionals, mainly from universities). Various dimensions of competency were included in the course, as well as other generic competencies, by adapting competencies to the activities implemented. The results of the drama techniques were evaluated based on the students' involvement in the project, through the resolution of problems and unexpected situations and through the delivery of effective communication and student satisfaction surveys. The project generated new information on ways of organising information, on ways of composing storylines and on ways of interpreting information to convey specific messages. The main objective of the project was to deliver interpretive messages through a communicative process during which students interact with the public through the dramatisation of the lives of female scientists.

The project was carried out in four stages described below. Both generic competencies corresponding to the course, as well as specific competencies corresponding to thematic interpretation, were tested:

\section{Stage 1: Outlining The Project And Selecting Characters}

Competencies: client guidance; interrelationship development; teamwork and cooperation; creativity

At this stage, students agreed to participate in the Polytechnic University of Valencia's project regarding the exhibition on "Women Scientists". 
The target audience of the exhibition was determined to adjust storylines to a comprehensible format while still adhering to the sociolinguistic customs of each time period. Short anecdotes were also adapted to more effectively convey specific messages.

As a fundamental part of this process, three characters were selected as a basis for dramatisation and the research achievements of these characters were identified. Ada Lovelace, Rosalin Franklin and Marie Curie were the three female scientists chosen for tour design and implementation. Groups were also created at this stage.

\section{Stage 2: Documenting And Creating Storylines}

Competencies: creativity; concern for order and quality; teamwork and leadership; time management and planning; documentation search and analysis

In the second stage, the biography of each selected female scientist was documented and storylines were developed. The period during which each female scientist lived was also documented for contextualisation. Topics and subtopics regarding knowledge and emotional connections were also identified at this stage.

A search for literature and audio-visual materials was conducted to document the lives of the female scientists and to acquire knowledge on their scientific achievements. In each biography, a common denominator appeared - their rejection from society as female researchers as well as their lack of integration resulting from sexist attitudes of the period. This was the case for Ada Lovelace, also known as the "Enchantress of numbers" who was rejected by her own family and for Rosalin Franklin who endured contempt from her colleagues (recipients of a Nobel Prize for research conducted by her).

Introductory statements on each female scientist were also developed at this stage for contextualisation purposes.

Stage 3: Selecting And Adapting Storylines, Securing Props, Costumes, Customising Characters, And Designing Itineraries

Competencies: designing and organising visits; teamwork; project design

Once the scenarios to be enacted were determined and once the scripts were edited, the locations of dramatisations throughout the Higher Polytechnic School of Gandia of the Polytechnic University of Valencia were determined. Chemistry and biotechnology labs were included in the itinerary and were used to recreate two performances.

Props (Picture 1) were also selected at this stage and the protagonists' costumes were collected using photos obtained during the previous documentation stage. Once the costumes were secured, the script and storyline sequence were determined. A student's narration was also created to connect the three personal stories. 


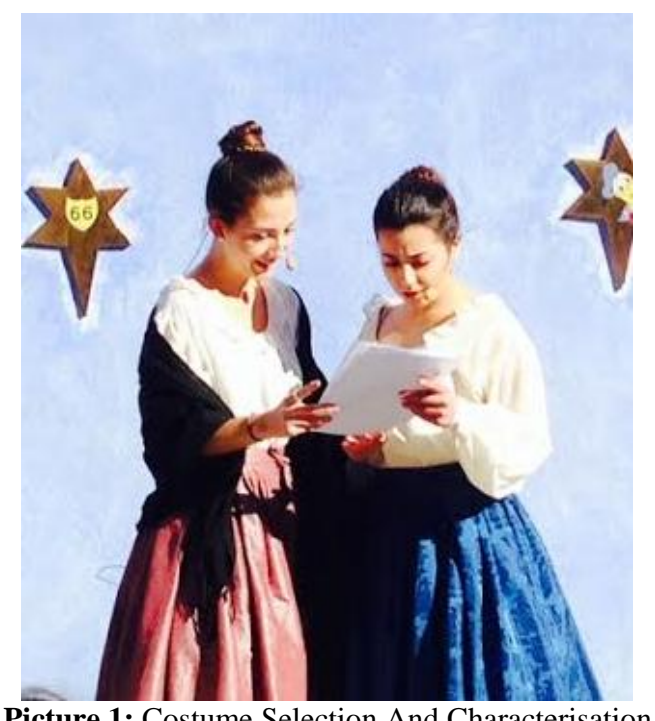

Picture 1: Costume Selection And Characterisation

Stage 4: Performing Interpretive Moments

Competencies: applying knowledge of languages; heritage interpretation

In this phase, the three interpreted historical moments are dramatised. The exercise tests competencies in applying dramatisation as an interpretative tool in an organised and entertaining manner in reference to a certain topic.

\section{DISCUSSION AND CONCLUSIONS}

Because there are few scientifically documented experiences of this type to compare the results, it may be concluded that the college students' experiences with dramatisation educational tools were positive. be observed.

The approach's validity as a method for the practical development of thematic interpretation instruction can

Feelings of motivation and satisfaction experienced by students involved in the project were evident. Thus, in addition to learning new skills, the students developed thematic interpretation capacities, or an ability to communicate while encouraging creativity and teamwork. A harmonious relationship was also established between teachers and students, as these two groups shared goals, aspirations and a common desire to do effective work.

It should also be reinforced that dramatisation is recognised as a strong interpretive tool for effective heritage interpretation that promotes the accumulation of cognitive and emotional knowledge among audiences.

The results of this teaching project demonstrate that it is necessary to include thematic interpretation instruction in tourism graduate degree curricula. Furthermore, the acquisition of competencies specific to heritage interpretation is now fundamental to the tour guide, who must forge connections between visitors and heritage destinations.

Through this teaching approach, students are actively involved in the learning experience, resulting in comprehensive training in the development of skills, abilities and aptitudes necessary for good heritage interpretation.

Future research efforts may explore other benefits of dramatisation as a tourism and heritage conservation instruction methodology. 


\section{AUTHOR INFORMATION}

Lola Teruel, Assistant Professor in the Economic Department, Polytechnic School of Gandia, Universitat Politècnica de València (Spain), has a Degree in Tourism, Communication and Public Relations by University of Alicante and a Degree in Advanced Studies in Economic by Universitat Politècnica de València. Research Interests include Tourism Management, Communication and Heritage. E-mail: dteruel@upv.es. (Corresponding author)

Dr. Maryland Morant, PhD by the Universitat Politècnica de València (UPV) (Spain). MSc in Environmental Management and Strategies, Universitat de València - Estudi General (UV) (Spain). Associate Professor, Dept. of Cartographic Engineering, Geodesy and Photogrammetry, Polytechnic University of Valencia. Research interest includes Tourism Management of Natural and Cultural Heritage. E-mail: marmogon@cgf.upv.es.

Dr. Maria José Viñals, PhD in Geography and Professor in Heritage Tourism Management at Architecture School in the Universitat Politécnica de Valencia (Spain). Research interest includes Tourism Management of Natural and Cultural Heritage. E-mail: mvinals@upv.es.

\section{REFERENCES}

1. Adcock, L. \&. (2007). Drama as a Tool in Interpretation: Practitioner Perceptions of its Strengths \& Limitations. Australian Journal of Environmental Education, 23.

2. Araujo, N. \&. (2011). El turismo inducido a través de las series de ficción y su papel dentro del turismo experiencial. El caso de la serie de ficción Doctor Mateo. . XVI Congreso AECIT. Retos para el turismo español, cambios de paradigma. Mijas_Malaga.

3. Armstrong, E. .. (2003). Applications of Role-Playing in Tourism Management Teaching: An Evaluation of a Learning Method. . Journal of Hospitality, Leisure, Sport and Tourism Education 2(1), , 5-16.

4. Bacher, K. e. (2007). Bases de la interpretación. Descripción del contenido del programa formativo. Universidad de Indiana: Programa de Desarrollo Interpretativo. .

5. Beck, L. C. (1998). Interpretation for the 21 st century. Fifteen Guiding Principles for Interpreting Nature and Culture. Cahmpaign, IL. USA.: Sagamore Publishing.

6. Bicknell, S. (1994). Enlightening or embarrassing?: Drama in the Science Museum, London, UK. Visitor Studies: Theory Research and Practice, (pp. 79-88). Jacksonville, Centre for Social Design.

7. Binkhorst, E. ( 2006). The eco-creation tourism experience. XV Congreso Internacional de Ocio y Turismo de ESADE. Barcelona.

8. Broughton, R. L. (2002). 2002 Ecotourism Association of Australia International Conference. Canberra, Australia: : Australian Heritage Commission and Ecotourism As.

9. Christensen, J. (2005). Interpretation can target everyone. National Association of Interpretation Legacy, 1 (1). .

10. Consejo, P. E. Directiva 2006/123/CE del Parlamento Europeo y del Consejo, de 12 de diciembre de 2006, relativa a los servicios en el mercado interior. (DOUEL núm. 376 de 27 de Diciembre de 2006).

11. Errington, E. (1997). Role-play. Canberra: Canberra: Higher Education Research and Development Society of Australasia Inc. .

12. EVALUACIÓN, A. N. (2004). Libro Blanco del Turismo .

13. Gaskell, I. \&. (2002). An analysis of the Wan Smolbag Theatre Company's impact on its audience. University of the South Pacific, Vanuatu: Unpublished research report,.

14. Goleman, D. \&. (1996). Emotional intelligence: Why it can matter more than IQ. Nature, 379(6560), 3434.

15. Ham, S. (2008). De la interpretación a la protección: ¿hay una base teórica? Boletín de Interpretación, 18. Asociación Intepretación del Patrimonio , pp. 27-31.

16. Ham, S. H. (1992). Interpretación Ambiental, Una Guía Práctica. Colorado: North American Press, .

17. Ham, S. (2011). La interpretación es persuasiva cuando el tema es convincente. Boletín de interpretación $n^{o}$ 25 -Asociación para la Interpretación del Patrimonio, España , 18-20. .

18. Jensen, R. (1999). Dream society: how the coming shift form information to imagination will transform your bisness. New York: McGraw-Hill. 
19. Jones, S. (2007). Sharing our stories. Guidelines for Heritage Interpretation. Perth: National Trust of Australia \& Museums Australia.

20. Lewis, W. (1981). Interpreting for Parks Visitors. 2nd ed. Charlottetown, Prince Edward Island, Canada.: Eastern National Parks and Monuments Association USA -Acorm Press. .

21. Ley 17/2009, de 23 de noviembre, sobre el Libre Acceso a las Actividades de Servicios. BOE, de 24.11.2009.

22. Mendoza-Ontiveros, M. U. (2011). La interpretación del patrimonio, una herramienta para el profesional del turismo . El periplo Sustentable, $n^{o} 20$, 9-30.

23. Ministerio de Educación, C. y. (2012).

24. Ministerio de Educación, C. y. (2012). Competencias para la inserción laboral, guía para el alumno. 75 pp.

25. Morales, J. (2000). Técnicas para la interpretación del patrimonio.Aspectos disciplinarios y procedimentales para la divulgación in situ del patrimonio natural y cultural. . Caracas: UPEL-IIPC.

26. Nwadigwe, C. E. (2007). Meet us at the other side of the river: Performance, venue and community education among migrant fishermen in Nigeria. Research in Drama Education, 12(1) , 65-77.

27. Pascoe, R. (1998). The language of drama: Making and communicating meaning. Canberra, Australia: Australian Centre for Arts Education.

28. Pine, B. \&. (1999). The experience economy, work is theatre and every business a stage. Boston: Harvard Business Scholl Press.

29. Powell, R. M. (1995). Drama, as a technique that can be used in environmental interpretation and education. Canberra, Australia : Masters thesis (042), University of Canberra, Australia.

30. Sánchez, J. \&. (2009). Nuevas tendencias en comunicación. Madrid: Esic Editorial.

31. Schmitt, B. H. (1999). Experiential marketing. Deusto: Deusto Ediciones, 298 pp.

32. Service., N. P. (2007). Foundational Competencies for All National Park Service Interpreters. http://www.nps.gov/idp/interp/101/FoundationsCurriculum.pdf (20/05/14).

33. Shively, C. A. (1995). Get provoked: Applying Tilden's principles. Legacy, July/August, 6-10. .

34. Smith, G. A. (1998). Creating a public of environmentalists: The role of nonformal education. In G. A. (Eds., Ecological education in action: On weaving education, culture, and the environment (pp. 207-225). Albany, NY: State University of New York Press.

35. Tilden, F. (1967). Intepreting Our Heritage (3rd Edition). Chapel Hill. University of North Carolina Press.

36. Turismo, S. G. (2007). Plan de Turismo Español Horizonte 2020. Madrid : Ministerio de Industria Comercio y Turismo.

37. Turismo, S. G. (2007). Plan de Turismo Español Horizonte 2020. Madrid: Ministerio de Industria, Turismo y Comercio.

38. Vera, B. (2008). Psicología positiva: una nueva forma de entender la psicología positiva. Madrid: Calamar Ediciones. 